\title{
Prevalence of thyroid disorders among patients attending the antenatal clinic at tertiary care centre, Parel, Mumbai, India
}

\author{
Jaya K. Gedam*, Disha A. Rajput
}

Department Obstetrics and Gynaecology, ESI PGIMSR MGM Hospital, Parel, Mumbai, Maharashtra, India

Received: 21 February 2017

Accepted: 02 March 2017

\author{
*Correspondence: \\ Dr. Jaya K. Gedam, \\ E-mail: jayagedam@gmail.com
}

Copyright: $(\odot$ the author(s), publisher and licensee Medip Academy. This is an open-access article distributed under the terms of the Creative Commons Attribution Non-Commercial License, which permits unrestricted non-commercial use, distribution, and reproduction in any medium, provided the original work is properly cited.

\begin{abstract}
Background: Pregnancy is associated with major changes in the physiology of the thyroid gland. Undiagnosed thyroid disorders can adversely affect fetal and maternal outcome. This study was done to study the prevalence of thyroid disorder among antenatal women.

Methods: This was a prospective study done in the antenatal clinic in the Department of Obstetrics and Gynaecology, ESI PGIMSRMGM Hospital, Parel, Mumbai, India.

Results: In present study, fifty out of three hundred and fifty pregnant women screened had thyroid disorder. The prevalence of thyroid disorder in this study was $14.2 \%$. The prevalence of subclinical hypothyroidism was $7.7 \%(\mathrm{n}=$ $27)$, overt hypothyroidism was $4 \%(\mathrm{n}=14)$, subclinical hyperthyroidism was $1.7 \%(\mathrm{n}=6)$ and overt hyperthyroidism was $0.8 \%(\mathrm{n}=3)$.

Conclusions: Thyroid disorders in pregnancy are associated with adverse fetomaternal outcome. Its prevalence is high in Indian women. Thus thyroid screening should be included in the routine antenatal investigations.
\end{abstract}

Keywords: Antenal women, Overt hyperthyroidism, Overt hypothyroidism, Subclinical hyperthyroidism, Subclinical hypothyroidism, Thyroid disorder

\section{INTRODUCTION}

Thyroid disorder is one of the commonest medical disorders in Indian pregnant women which can adversely affect fetal and maternal outcome. Two pregnancy related hormones - human chorionic gonadotropin ( $\mathrm{Hcg}$ ) hormone and estrogen hormone cause increased thyroid hormone levels in the blood. Hcg is secreted by placenta and is similar to thyroid stimulating hormone (TSH) and stimulates the thyroid to produce more thyroid hormone. During pregnancy increased estrogen produces higher levels of thyroid-binding globulin, a protein that transports thyroid hormone in the blood. These normal hormonal changes can sometimes make thyroid function tests difficult to interpret.

Thyroid hormone is very important for fetal brain and nervous system development and thus fututure intellectual development. During organogenesis and first trimester, the fetus gets thyroid hormone through mother via placenta. At around 12 weeks, the fetal thyroid begins to produce thyroid hormone on its own.

According to western world prevalence of hypothyroid disorders in pregnancy is $2.5 \%$ and hyperthyroidism in pregnancy is $0.1 \%$ to $0.4 \% .^{1}$ Thyroid disorder in pregnancy is more in South Asian women especially Indian women. A few studies showed a prevalence of thyroid disorder in pregnancy $4.8 \%$ to $11 \%$. $^{2,3}$

Thyroid disorders in pregnancy are mostly caused by autoimmune disorder. Hypothyroidism in pregnancy is usually caused by Hashimoto's disease and occurs in three to five out of every 1,000 pregnancies. ${ }^{4}$ Hashimoto's disease is a form of chronic inflammation of the thyroid gland. Hyperthyroidism in pregnancy is usually caused by Graves' disease and occurs in about one of every 500 
pregnancies. ${ }^{5}$ Graves' disease is an autoimmune disorder. Thyroid disorders are difficult to diagnose during pregnancy due to symptoms similar to both pregnancy and thyroid disorders. Therefore this prospective study was done to find out the prevalence of thyroid disorders in antenatal women.

\section{Aims and objectives}

- To determine the prevalence of thyroid disorders among patients attending the antenatal clinic.

- To diagnose subclinical as well as overt thyroid disorders early.

- To manage the patients with thyroid disorders appropriately.

\section{METHODS}

This study was conducted on patients attending the antenatal clinic at obstetrics and Gynaecology department at ESI-PGIMSR MGM Hospital, Parel over the 6 months period from December 2014 to May 2015 after institutional ethical committee approval. This was a hospital based prospective study done on randomly selected 350 antenatal patients who fulfilled the inclusion criteria during their first antenatal visit irrespective of period of gestation.

\section{Study group}

350 antenatal pregnant patients attending the antenatal Clinic were enrolled as per the inclusion and exclusion criteria.

\section{Place/area of study}

The study was conducted at ESI-PGIMSR MGM Hospital, Parel, Mumbai, India.

Design of the study was a Prospective study over 6 months from the commencement of the project.

\section{Inclusion criteria}

- Patients attending the antenatal clinic

- Consenting to take part in the study

- Singleton pregnancy

\section{Exclusion criteria}

- Known cases of Thyroid disorders

- Multiple pregnancy

- Gestational trophoblasic disease

- Any medical co-morbidities

- Previous history of Thyroid surgery or use of radioiodine therapy

Written informed consent was taken after explaining the nature of study and voluntary participation. Detailed history related to age, gestational age, past and present medical history (thyroid and other medical disorders) and surgical history was taken. Family history, personal history, menstrual and obstetric history was taken. Thorough general physical examination was done. Patients were subjected to systemic and obstetric examination. Along with routine blood investigations included in our antenatal profile complete blood picture, Blood grouping and $\mathrm{Rh}$ typing, Random blood sugar, Liver function test, Kidney function test, HBsAg, VDRL, HIV, complete urine examination, serum levels of Free T3 and T4 as well as TSH levels were also determined. Test results were collected and the patients were managed accordingly.

As per the guidance of American thyroid disorder association for the diagnosis and management of thyroid disease during pregnancy, Laboratory reference range:

- $\quad$ Free T3: $1.7-4.2 \mathrm{pg} / \mathrm{ml}$

- Free T4: $0.7-1.8 \mathrm{ng} / \mathrm{dl}$

- TSH: $0.35-5.5 \mathrm{mIU} / 1$

Trimester wise cut off values for TSH are

- First trimester: 0.1-2.5mIU/L

- Second trimester: 0.2-3mIU/L

- Third trimester: 0.3-3 mIU/L

\section{Criteria for thyroid dysfunction}

Overt hypothyroidism

Low FreeT3, FreeT4 along with elevated TSH.

Subclinical hypothyroidism

FreeT3, FreeT4 in normal range along with TSH more than $2.5 \mathrm{mIU} / \mathrm{L}$.

Overt hyperthyroidism

FreeT3, FreeT4 in normal range along with elevated TSH. Subclinical hyperthyroidism

FreeT3, FreeT4 in normal range along with TSH less than $0.1 \mathrm{mIU} / \mathrm{L}$. Using these cutoff values thyroid dis-function during pregnancy is determined.

\section{Statistical analysis}

The data were compiled and analysed using appropriate statistical tests. Continuous variables are presented as mean \pm SD and analyzed using unpaired, two-tailed students t-test. categorical variables are presented as absolute number and percentage. Proportional data were compared using Chi-square test. $\mathrm{P}$ value $<0.05$ was considered statistically significant. 


\section{RESULTS}

In present study, fifty out of three hundred and fifty pregnant women screened had thyroid disorder. As shown in Figure 1. The prevalence of thyroid disorder in this study was $14.2 \%(n=50)$. The prevalence of sub-clinical hypothyroidism was $7.7(\mathrm{n}=27)$, overt hypothyroidism was $4 \%(n=14)$. Sub clinical hyperthyroidism was $1.7 \%(n=6)$ and overt hyperthyroidism was $0.8 \%(\mathrm{n}=3)$.

Table 1: Prevalence of thyroid disorder.

\begin{tabular}{|lll|}
\hline Thyroid disorder & Prevalence & \\
\hline & Number (n) & Percentage \\
\hline Subclinical hypothyroid & 27 & 7.7 \\
\hline Overt hypothyroid & 14 & 4 \\
\hline Subclinical hyperthyroid & 6 & 1.7 \\
\hline Overt hyperthyroid & 3 & 0.8 \\
\hline Total & 50 & 13.2 \\
\hline
\end{tabular}

Maternal demographic characteristics are shown in Table 1 , in group I (subclinical and overt hypothyroid) 62\% pregnant patient were in age group 18-30 years, where as in group II (subclinical and overt hyperthyroid) $12 \%$ patients were in age group 31-40 years. Chi square static is $6.0617, \mathrm{P}$ Value is 0.0138 . The difference in age in between two group was statistically significant at $\mathrm{P}<0.05$.

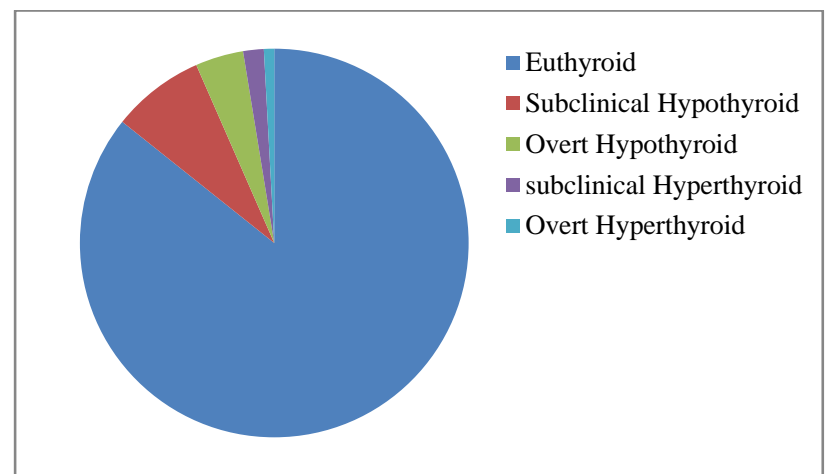

Euthyroid 85.7\%, Subclinical Hypothyroid 7.7\%, Overt Hypothyroid 4\%, Subclinical Hyperthyroid 1.7\%, Overt Hyperthyroid $0.8 \%$

Figure 1: Prevalence of thyroid disorder.

Table 2: Maternal demographic characteristics.

\begin{tabular}{|c|c|c|c|c|c|c|}
\hline \multirow[t]{3}{*}{ Variables } & \multirow{2}{*}{\multicolumn{2}{|c|}{$\begin{array}{l}\text { Subclinical and overt } \\
\text { hypothyroid }(n=41)\end{array}$}} & \multirow{2}{*}{\multicolumn{2}{|c|}{$\begin{array}{l}\text { Subclinical and overt } \\
\text { hyperthyroid }(n=9)\end{array}$}} & \multirow{3}{*}{$\begin{array}{l}\text { Chi square } \\
\text { static }\end{array}$} & \multirow{3}{*}{$P$ value } \\
\hline & & & & & & \\
\hline & Number & Percentage & Number & Percentage & & \\
\hline \multicolumn{7}{|c|}{ Age (years) } \\
\hline $18-30$ & 31 & 75.6 & 3 & 33.3 & \multirow{2}{*}{6.0617} & \multirow{2}{*}{$0.0138 *$} \\
\hline $31-40$ & 10 & 24.4 & 6 & 66.6 & & \\
\hline \multicolumn{7}{|l|}{ Parity } \\
\hline Primi & 13 & 31.7 & 7 & 77.7 & \multirow{2}{*}{6.52} & \multirow{2}{*}{$0.0106 *$} \\
\hline Multi & 28 & 68.3 & 2 & 22.2 & & \\
\hline \multicolumn{7}{|c|}{ Gestational age (weeks) } \\
\hline $6-12$ & 29 & 70.07 & 6 & 66.6 & \multirow{3}{*}{0.1505} & \multirow{3}{*}{0.92753} \\
\hline $13-28$ & 9 & 21.95 & 2 & 22.2 & & \\
\hline $29-40$ & 3 & 00.07 & 1 & 11.1 & & \\
\hline
\end{tabular}

*Result is significant at $\mathrm{P}<0.05$.

In group I (subclinical and overt hypothyroid) $56 \%$ pregnant patient were multigravida, where as in group II (subclinical and overt hyperthyroid) $14 \%$ patients were primigravida. Chi square static is 6.52, $\mathrm{P}$ Value is 0.01062 . Result was statistically significant at $\mathrm{P}<0.05$.

Mean gestational age was $7.96 \pm 2.01$ weeks in group I (subclinical and overt hypothyroid), where as in group II (subclinical and overt hyperthyroid) mean gestational age was 7.738+-8.181 weeks. Mean gestational weeks were not statistically significant $(\mathrm{P}>0.05)$ in unpaired t-test.

The number of one abortions were common in group I (subclinical and overt hypothyroid) 32\% pregnant patients than that of group II (subclinical and overt hyperthyroid)
$12 \%$ patients. Chi square static is $1.451, \mathrm{P}$ Value is 0.484 . Result was not statistically significant at $\mathrm{P}<0.05$. The number of women conceived between 1 to 2 years of marriage were $56 \%$ in group I (subclinical and overt hypothyroid) than that of $12 \%$ pregnant patients group II (subclinical and overt hyperthyroid). Chi square static is 12.85, $\mathrm{P}$ Value is 0.0016. Result was statistically significant at $\mathrm{P}<0.05$.

Many women with thyroid disorder have anovulatory cycles and after conception abortion rates are high as compare to spontaneous abortion in Euthyroid pregnant women. $^{6}$ 
In this study mean TSH level was $4.5 \pm 1.19 \mathrm{uIU} / \mathrm{ml}$ in group I (subclinical and overt hypothyroid) pregnant patients. Where as in group II (subclinical and overt hyperthyroid) mean TSH level was $0.05 \pm 0.0273 \mathrm{uIU} / \mathrm{ml}$. Unpaired $t$ test showed two tailed $P$ value of $<0.0001$. This difference was statistically significant at $\mathrm{P}<0.05$.

Mean $\mathrm{FT}_{3}$ level was $2.1 \pm 1.401$ in pregnant patients of group I (subclinical and overt hypothyroid), where as in group II (subclinical and overt hyperthyroid) mean $\mathrm{FT}_{3}$ level was $0.05 \pm 0.027$. Unpaired t test showed two tailed $\mathrm{P}$ value of $<0.0001$. This difference was statistically significant at $\mathrm{P}<0.05$.

Mean $\mathrm{FT}_{4}$ level $0.9268 \pm 0.497$ in pregnant patients of group I (subclinical and overt hypothyroid), where as in group II (subclinical and overt hyperthyroid) mean FT4 level was $1.555 \pm 0.3205$. Unpaired t test showed two tailed $P$ value of 0.1945 . This difference was not statistically significant at $\mathrm{P}<0.05$. Most of the hypothyroid pregnant women were managed with L- thyroxine (50-100ug/day) and Propylthiouracil was used for hyperthyroid pregnant women.

Table 3: Obstetrical variable.

\begin{tabular}{|c|c|c|c|c|c|c|}
\hline \multirow{3}{*}{ Variables } & \multirow{2}{*}{\multicolumn{2}{|c|}{$\begin{array}{l}\text { Subclinical and overt } \\
\text { hypothyroid }(n=41)\end{array}$}} & \multirow{2}{*}{\multicolumn{2}{|c|}{$\begin{array}{l}\text { Subclinical and overt } \\
\text { hyperthyroid }(\mathbf{n = 9})\end{array}$}} & \multirow{3}{*}{$\begin{array}{l}\text { Chi square } \\
\text { static }\end{array}$} & \multirow{3}{*}{$P$ value } \\
\hline & & & & & & \\
\hline & Number & Percent & Number & Percent & & \\
\hline \multicolumn{7}{|c|}{ Previous abortion } \\
\hline 1 Abortion & 16 & 39.02 & 6 & 66.6 & \multirow{3}{*}{1.451} & \multirow{3}{*}{0.484} \\
\hline 2 Abortion & 6 & 0.14 & 1 & 11.1 & & \\
\hline 3 Abortion & 3 & 0.07 & 1 & 11.1 & & \\
\hline \multicolumn{7}{|c|}{ Conception after marriage } \\
\hline$<1$ year & 8 & 19.5 & 1 & 11.1 & \multirow{3}{*}{12.85} & \multirow{3}{*}{$0.0016^{*}$} \\
\hline $1-2$ years & 28 & 68.3 & 2 & 22.2 & & \\
\hline $3-5$ years & 5 & 1.2 & 6 & 66.6 & & \\
\hline
\end{tabular}

* Result is significant at $\mathrm{P}<0.05$

Table 4: Distribution of TSH levels and FT4 levels in study group.

\begin{tabular}{|c|c|c|c|}
\hline \multirow{3}{*}{ Variables } & Group I & \multicolumn{2}{|l|}{ Group II } \\
\hline & $\begin{array}{l}\text { Subclinical and overt hypothyroid } \\
(n=41)\end{array}$ & $\begin{array}{l}\text { Subclinical and overt hyperthyroid } \\
(n=9)\end{array}$ & $P$ value \\
\hline & Mean \pm SD & Mean \pm SD & \\
\hline TSH (uIU/ml) & $4.5 \pm 1.19$ & $0.05 \pm 0.0273$ & $<0.0001 *$ \\
\hline FT4 (ug/dl) & $0.926 \pm 0.497$ & $1.155 \pm 0.0320$ & 0.1945 \\
\hline
\end{tabular}

*Unpaired $\mathrm{t}$ test- the two tailed $\mathrm{P}$ value is $<0.0001$. It is statistically significant

\section{DISCUSSION}

Prevalence of hypothyroidism in pregnancy is $2.5 \%$ in west to 11 in India\%. ${ }^{7}$ Prevalence is more in Asian countries. ${ }^{8}$ Our study was done in 350 pregnant patients irrespective of the period of gestation which is comparable to study by Thanuja PM et al, who studied 300 women. ${ }^{9}$ Our study was also comparable to the study of Sahu M et al, who studied 633 women in second trimester and Srinivas Rao et al, who studied 1062 cases., , $^{30}$

The occurrence of thyroid disorders in our study was $14.2 \%$. Our findings are consistent with the reports from the study of Sahu M et al, who studied 633 women in second trimester. In their study the prevalence of thyroid disorders was $12.7 \%$, which is comparable to our study. ${ }^{3}$ Our study is not comparable with Thanuja PM et al, where prevalence of thyroid disorder was $5 \% .^{9}$ The occurrence of subclinical hypothyroidism in our study was $7.7 \%$. In the study of Sahu MT et al the prevalence was $6.47 \%$, which is comparable to our study. ${ }^{3}$ Thanuja PM et al showed prevalence of $0.7 \%$ which is very low and not comparable to our study. ${ }^{9}$ In a study done by Casey BM et al, the prevalence was $23 \%$ which is very high and not consistent with our study. ${ }^{11}$

The occurrence of overt hypothyroidism in our study was $4 \%$, which is consistent with a study done by Sahu MT et al, in which the prevalence is $4.58 \% .^{3}$ Thanuja PM et al showed prevalence of $1 \%$ which is very low and not comparable to our study. ${ }^{9}$ Dhanwal et al in 2013 reported a hypothyroidism prevalence of $14.3 \%$, with a cut off of $4.5 \mathrm{~m} \mathrm{IU/L}$ as upper limit of normal in a cohort of 1000 pregnant women. ${ }^{12}$ Study by Marty $\mathrm{N}$ et al had shown a prevalence of $26 \%$ at a cut off of $3.0 \mathrm{~m} \mathrm{IU/L}$ as per ATA Guidelines. ${ }^{13}$ The occurrence of subclinical and overt hyperthyroidism in our study was $1.7 \%$ and 0.8 respectively. In a study done by Sahu MT et al, the 
prevalence was $0.9 \%$ and $0.7 \%$ for subclinical and overt hyperthyroidism. ${ }^{3}$ Thanuja PM et al showed prevalence of $1.3 \%$ and $2 \%$ respectively which is comparable to our study. ${ }^{9}$ The prevalence of sublinical hyperthyroidism is comparable with other studies. In a study done by Mannisto $\mathrm{T}$ et al, the prevalence was $3.5 \% \& 1.3 \%$ for subclinical and overt hyperthyroidism. ${ }^{14}$ The prevalence of Subclinical and Overt Hyperthyroidism was 0.5 and $0.4 \%$ respectively in a study done by Stagnaro Green. ${ }^{15}$ Various reasons have been proposed for increased prevalence of hypothyroidism in pregnancy in Asia. Increased iodine intake in diet, presence of goitrogens in diet as reported from studies in India, deficiency of micronutrients like selenium and iron, are some of the reasons for high Hypothyroidism prevalence in India. ${ }^{16-18}$

\section{CONCLUSION}

Our study concludes that there is a high prevalence of thyroid dysfunction, mostly subclinical hypothyroidism. Therefore universal screening for thyroid disorder should be included in routine antenatal care.

\section{ACKNOWLEDGEMENTS}

Author would like to thank the Institutional Research committee for supporting us through the study.

Funding: No funding sources

Conflict of interest: None declared

Ethical approval: The study was approved by the Institutional Ethics Committee

\section{REFERENCES}

1. LeBeau SO, Mandel SJ. Thyroid disorders during pregnancy. Endocrinol Metab Clin North Am. 2006;35:117-36.

2. Nambiar V, Jagtap VS, Sarathi V, Lila AR, Kamalanathan S, Bandgar TR, et al. Prevalence and impact of thyroid disorders on maternal outcome in Asian-Indian pregnant women. J Thyroid Res. 2011;2011:4290-7.

3. Sahu MT, Das V, Mittal S, Agarwl A, Sahu M. Overt and subclinical thyroid dysfunction among Indian pregnant women and its effect on maternal and fetal outcome. Arch Gynecol Obstet. 2010;281:215-20.

4. Ogunyemi DA. Autoimmune thyroid disease and pregnancy. eMedicine website. www.emedicine.medscape.com/article/261913overview . Updated April 23, 2010. Accessed August 11, 2011.

5. Komal PS, Mestman JH. Graves hyperthyroidism and pregnancy: a clinical update. Endocrine Practice. 2010;16(1):118-2.
6. Montoro MN. Management of hypothyroidism during pregnancy, Clin Obstat Gynecol. 1997;40:65-80.

7. Stagnaro-Green A. Thyroid antibodies and miscarriage: Where are we a generation later? J Thyroid Res. 2011;2011:841-49.

8. Wang W, Teng W, Shan Z, Wang S, Li J, Zhu L, et al. The prevalence of thyroid disorders during early pregnancy in China: The benefits of universal screening in the first trimester of pregnancy. Eur J Endocrinol. 2011;164:263-8.

9. Thanuja PM, Rajgopal K, Sadiqunnisa. Thyroid dysfunction in pregnancy and its maternal outcome. Journal Dental and Medical Sciences (IOSR-JDMS): 2279-0861. 2014;13(1):11-5.

10. Rao S, Patibandla A. A Study to find out the Prevalence of Hypothyroidism among Pregnant Women Visiting ESI Hospital Sanathnagar Hyderabad. Gynecol Obstet. 2016;6:363.

11. Casey BM, Dashe JS, Wells CE, McIntire DD, Byrd W, Leveno KJ, Cunningham FG. Subclinical hypothyroidism and pregnancy outcomes. Obst Gynec. 2005;105(2):239-45.

12. Dhanwal DK, Sudha P, Agarwal AK, Dixit V, Banerjee AK. High prevalence of subclinical hypothyroidism during first trimester of pregnancy in North India. Ind $\mathrm{J}$ Endocrinol Metab. 2013;17:281-4.

13. Murty Nabhi VR, Bhashyakarla U. Prevalence of Thyroid Dysfunction among Pregnant Women in a Rural Teaching Hospital in Telengana, South India Scholars. Journal of Applied Medical Sciences. 2014;2(6B):20225 .

14. Mannisto T, Vaarasmaki M, Pouta A, Hartikainen AL, Ruokonen A, Surcel HM, Bloigu A, et al. Thyroid dysfunction and maternal morbidity. J Clin Endocrinol Metab. 2010;95(3):1084-1094.

15. Stagnaro GA. Overt Hyperthyroidism and Hypothyroidism during pregnancy. Clin Obstet Gynaecol. 2011;54(3):478-82.

16. Teng X, Shan Z, Chen Y, Lai Y, Yu J, Shan L, et al. More than adequate iodine intake may increase subclinical hypothyroidism and autoimmune thyroiditis: A crosssectional study based on two Chinese communities with different iodine intake levels. Eur J Endocrinol. 2011;164:943-50.

17. Marwaha RK, Tandon N, Gupta N, Karak AK, Verma K, Kochupillai N. Residual goitre in the postiodization phase: Iodine status, thiocyanate exposure and autoimmunity. Clin Endocrinol (Oxf). 2003;59:672-81.

18. Das S, Bhansali A, Dutta P, Aggarwal A, Bansal MP, Garg D, et al. Persistence of goiter in the postiodization phase. Micronutrioent deficiency or thyroid autoimmunity? Indian J Med Res. 2011;133:103-9.

Cite this article as: Gedam JK, Rajput DA.

Prevalence of thyroid disorders among patients attending the antenatal clinic at tertiary care centre, Parel, Mumbai, India. Int J Reprod Contracept Obstet Gynecol 2017;6:1235-9. 